\title{
PERFORMANCE EVALUATION OF COMMERCIAL BANKS IN NEPAL USING AHP
}

\author{
Ashish Bhandari ${ }^{*}$ \\ Mechanical Engineering Department \\ Institute of Engineering \\ Tribhuvan University \\ Lalitpur, Nepal \\ E-mail: aashishbhandari@gmail.com,068mstim152@ioe.edu.np \\ Amrit Man Nakarmi \\ Mechanical Engineering Department \\ Institute of Engineering \\ Tribhuvan University \\ Lalitpur, Nepal \\ E-mail: amritnakarmi@ioe.edu.np
}

\begin{abstract}
This paper explores the determinants of performance exposed by the financial ratios and determines the financial performance of commercial banks in Nepal through Analytical Hierarchy Process based on their financial characteristics. The financial parameters were derived by segregating 5 major criteria which were Liquidity, Efficiency, Profitability, Capital Adequacy and Assets Quality. These criteria were further classified into 21 hierarchical sub-criteria. The performance evaluation was done for 13 commercial banks for financial data from year 2008/09 to 2011/12. The paper emphasizes financial decision problems to have strong multi criteria character and establishes priorities for performance parameters of commercial banks among financial indicators identified and ranks banks according to those indicators. This study has added one more literature to demonstrate the utility of AHP based bank evaluation to Nepalese banking community in particular, which not only evaluates the performance of banks but also gives insights to focus in the area of improvement to a particular bank in comparison to others.
\end{abstract}

Keywords: Banking, Financial Ratios, AHP, Performance Evaluation

\section{Introduction}

On the basis of ownership, the commercial banks in Nepal can be categorized into two groups as public and private banks. As of mid-July 2012 there are 3 public banks and 29 private sector banks. In the light of the very fact that commercial banks are the backbone of the economy of a country, it is highly useful to make the present study on the commercial banks. This research will explore the key financial performance indicators based on Analytical Hierarchy Process and identify how these are affecting banks' performance. In order to identify the key performance indicators the focus research question is a) Based on your values, what are the main characteristics of an efficient 
bank? b) Is Public Banks efficient than Private Banks? c) How can efficiency of Banks be evaluated?

\section{Literature Review}

\subsection{Performance Evaluation of Banks}

The traditional performance rankings of banks is based on simple and consistent factors such as financial returns, Returns on Asset (ROA) and Returns on Earning (ROE). Nevertheless, performance rankings conducted in this way may not precisely illustrate institutions that embrace strategies for sustaining top performance (Hanley \& Suter, 1997). (Gilbert, Meyer, \& Vaughan, 2002) suggest used off-site tools are supervisory screens (financial ratios from periodic balance sheets and income statements ) and econometric models (information from financial ratios). Nepal Rastra Bank's Banking Supervision Department (BSD) forsees bank performance based on six major components of bank safety and soundness that are collectively known as CAMELS (Capital Adequacy, Asset Quality, Management competence, Earning, Liquidity, Sensitivity to Market Risk) on a scale from 1 (robust) to 5 (very unstable).

\subsection{Bank Performance Evaluation by AHP}

The application of AHP in banking performance has been research interest after the late 1990's and most of the significant applications of AHP is found after 2000. (Jabalameli et al, 2011), (Hunjak et al, 2001) have used (DEA-AHP) to evaluate bank performance. (Lu et al, 2013) in their study used (AHP) to evaluate bank's operation risk rating in various stressed scenarios and to prioritize rating items. (Babićet al, 1999) rates the banks against the following six criteria equity capital, capital/assets ratio, profit/income ratio, Economic Value Added, organization efficiency and Value Added Intellectual Capital. (Čehulićet al, 2011) have used financial ratios into four groups Balance Sheet Ratios, Income Statement Ratios, Profitability Ratios and Market Ratios and several subgroups to analyze banks in Croatia by Analytical Hierarchy Process. Furthermore (Bhattarai et al, 2009) also convey the imperativeness of the ability of integrated/holistic decision analysis, putting subjective and objective information on the single framework for decision analysis in financial institutions in Nepal.

\section{Hypotheses/Objectives}

\section{Specific Objectives}

a. Review of AHP based bank assessment literature and contributing to the gap

b. Establishment of priorities for performance measurement of commercial banks among liquidity, efficiency, profitability, capital adequacy and asset quality indicators

c. Development and utilization of AHP based framework to evaluate commercial banks in Nepal

\section{Research Design/Methodology}

\subsection{Selection of Banks and Development of Hierarchy for purpose of study}

13 commercial banks including 3 Public sector banks were selected for the analysis in this study. Average of four year ratios from 2008/09 to 2011/12 was evaluated. The selection of major criteria's and sub criteria were based on literature findings, Nepal Rastra Bank's Key performance Indicators and Literature Reviews. The set of AHP 
IJAHP Article: Mu, Saaty/A Style Guide for Paper Proposals To Be Submitted to the International Symposium of the Analytic Hierarchy Process 2014, Washington D.C., U.S.A.

questionnaire was constructed and analyzed through Expert Choice Software ver. 11. 13 expert pairwise comparison were collected for analysis.

\section{AHP Model}

Figure 1 AHP Model for Bank Performance Evaluation

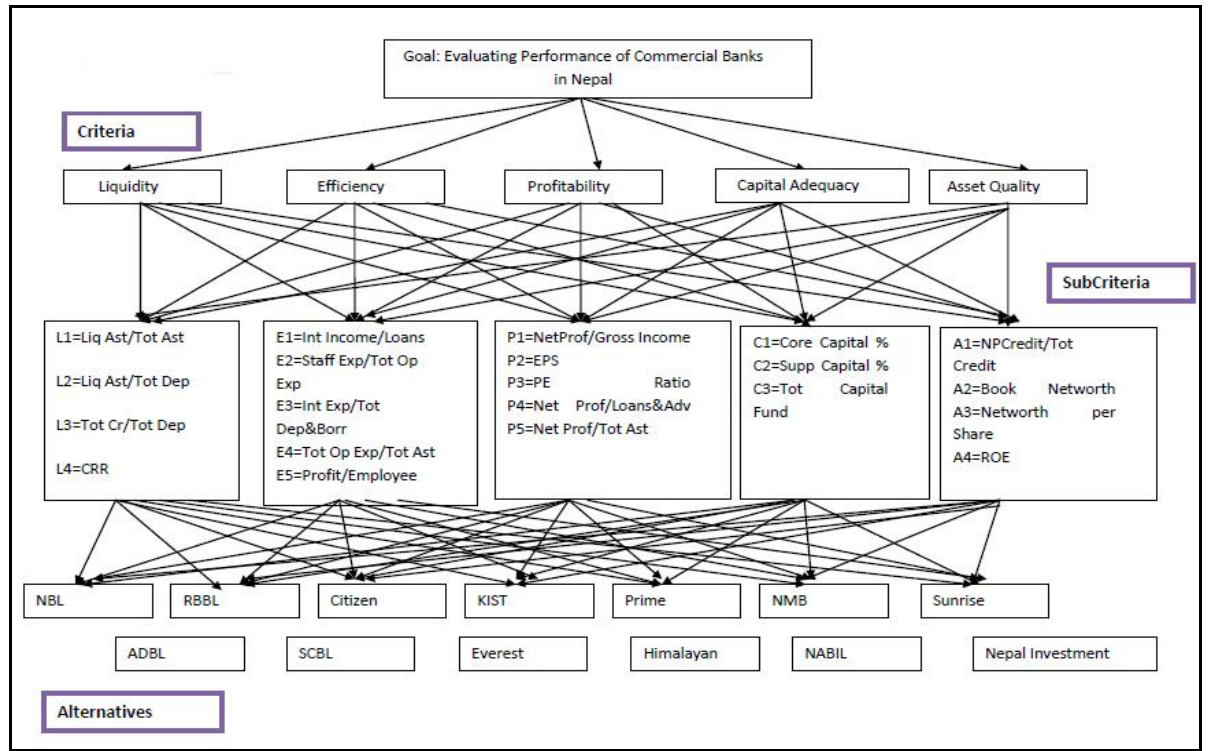

\section{Data/Model Analysis}

\subsection{Financial Analysis}

The mean financial values were calculated from the Annual reports of the respective banks and the table below shows the data

Table 1 Calculation of Financial Parameters

\begin{tabular}{|c|c|c|c|c|c|c|c|c|c|c|c|c|c|c|c|c|c|c|c|c|c|c|}
\hline & \multicolumn{4}{|c|}{ Liquidity } & \multicolumn{6}{|c|}{ Efficiency } & \multicolumn{5}{|c|}{ Profitability } & \multicolumn{3}{|c|}{ Capital Adequacy } & \multicolumn{4}{|c|}{ Asset Quality } \\
\hline & L1 & L2 & L3 & L4 & E1 & & E2 & E3 E & E4 & E5 & P1 & P2 & P3 & P4 & P5 & C1 & C2 & C3 & A1 & A2 & A3 & A4 \\
\hline Sunrise & 0.26 & & \begin{tabular}{l|l}
0.32 & 0.8 \\
\end{tabular} & 029.5 & & 9.07 & 44.54 & 6.8 & 1.93 & 288.07 & 8.24 & 7.71 & 29.18 & & $\begin{array}{ll}.90 .006 \\
\end{array}$ & \begin{tabular}{l|l|}
6 & 11.48 \\
\end{tabular} & 0.795 & \begin{tabular}{|l|l|}
5 & 12.2 \\
\end{tabular} & 70.038 & 1747462 & 107.17 & 70.08 \\
\hline Prime & 0.23 & & $\begin{array}{lll}0.26 & 0.8 \\
\end{array}$ & \begin{tabular}{l|l}
3 & 12.4 \\
\end{tabular} & & 1.78 & 33.81 & 7.2 & 11.1 & 1146.19 & 13.69 & 19.49 & 12.59 & & \begin{tabular}{ll|l|}
8 & 1.323 \\
\end{tabular} & \begin{tabular}{|l|l|}
311.39 \\
\end{tabular} & 0.918 & \begin{tabular}{l|l}
8 & 12.3 \\
\end{tabular} & 10.333 & 1433152.589 & 118.63 & $\begin{array}{ll}3.20 \\
\end{array}$ \\
\hline NMB & 0.36 & & \begin{tabular}{l|l}
0.60 & 0.8 \\
\end{tabular} & 010.4 & & 9.75 & 41.01 & 6.2 & 1.29 & 723.19 & 11.07 & 7.19 & 56.80 & 1. & .40 .820 & 016.66 & 0.598 & \begin{tabular}{l|l|}
8 & 17.5 \\
\end{tabular} & 20.983 & 1977676 & 114.57 & 70.07 \\
\hline KIST & 0.25 & & \begin{tabular}{l|l}
0.30 & 0.7 \\
\end{tabular} & 97.66 & & 2.62 & 37.86 & 7.5 & 2.05 & 193.88 & 17.47 & 4.85 & 48.36 & 0.5 & .90 .570 & \begin{tabular}{|l|l|}
0 & 14.45 \\
\end{tabular} & 0.765 & \begin{tabular}{|l|l|}
5 & 15.2 \\
\end{tabular} & 21.723 & 2117802.25 & 105.89 & 0.05 \\
\hline Citizen & 0.22 & & $\begin{array}{ll}0.26 & 0.8 \\
\end{array}$ & 112.7 & & 2.83 & 32.05 & 7.1 & 3.79 & 853.96 & 11.35 & \begin{tabular}{|l|l|}
5 & 14.19 \\
\end{tabular} & 32.80 & 1. & $\begin{array}{l}.61 .078 \\
\end{array}$ & \begin{tabular}{l|l|}
812.39 \\
\end{tabular} & 0.875 & \begin{tabular}{l|l}
5 & 13.2 \\
\end{tabular} & $\begin{array}{ll}70.873 \\
\end{array}$ & 1737627.9 & 109.00 & 0.11 \\
\hline RBBL & 0.31 & & $\begin{array}{ll}0.35 & 0.4 \\
\end{array}$ & \begin{tabular}{l|l}
9 & 13.0 \\
\end{tabular} & & 9.94 & 42.26 & 2.5 & 4.97 & 826.01 & 26.33 & \begin{tabular}{|l|l|}
3 & 432.68 \\
\end{tabular} & 0.00 & 4.7 & .72 .163 & 3 - 19.14 & 0.000 & $\begin{array}{l}0-19.1 \\
\end{array}$ & 40.109 & -8446908.76 & -720.54 & $4-0.20$ \\
\hline ADBL & 0.20 & & \begin{tabular}{l|l}
0.32 & 1.0 \\
\end{tabular} & $\begin{array}{l}7 \\
27.4 \\
\end{array}$ & & 3.96 & \begin{tabular}{|l|}
47.24 \\
\end{tabular} & 5.1 & 9.17 & 615.83 & 17.65 & 62.92 & 1.06 & \begin{tabular}{l|l}
6 & 4.5 \\
\end{tabular} & 43.053 & \begin{tabular}{|l|l|}
3 & 13.98 \\
\end{tabular} & 34.273 & \begin{tabular}{l|l}
3 & 18.2 \\
\end{tabular} & 59.663 & 11636569.75 & 422.37 & $\begin{array}{ll}7 & 0.18 \\
\end{array}$ \\
\hline NBL & 0.21 & & \begin{tabular}{l|l}
0.25 & 0.7 \\
\end{tabular} & \begin{tabular}{|l|l|}
523.6 \\
\end{tabular} & & 3.41 & 55.44 & 2.5 & 7.4 & 738.80 & 8.74 & $\begin{array}{l}495.19 \\
\end{array}$ & 0.00 & 1.7 & .70 .748 & 8 - -10.26 & 0.000 & $\begin{array}{ll}0 & -10.2 \\
\end{array}$ & 60.016 & -1200 & -315.47 & 70.05 \\
\hline NABIL & 0.21 & & $\begin{array}{ll}0.25 & 0.7\end{array}$ & \begin{tabular}{l|l}
56.38 \\
\end{tabular} & & 1.15 & \begin{tabular}{|l|}
15.48 \\
\end{tabular} & 4.9 & 5.88 & 3432.54 & 25.18 & \begin{tabular}{|l|l|}
8 & 87.87 \\
\end{tabular} & 26.39 & $\begin{array}{l}9 . \\
9 .\end{array}$ & 82.538 & \begin{tabular}{l|l|}
8 & 8.91 \\
\end{tabular} & 1.788 & \begin{tabular}{l|l|}
8 & 10.7 \\
\end{tabular} & 00.016 & 4249064.929 & 270.75 & \begin{tabular}{|l|l|}
5 & 0.31 \\
\end{tabular} \\
\hline Nepal Investment & 0.22 & & \begin{tabular}{l|l}
0.25 & 0.8 \\
\end{tabular} & \begin{tabular}{l|l}
0 & 9.8 \\
\end{tabular} & & 1.23 & 40.35 & 5.7 & 1.2 & 2022.92 & 20.40 & 39.15 & 19.88 & 2. & \begin{tabular}{ll|}
71.875 \\
\end{tabular} & \begin{tabular}{|l|l|}
5 & 8.79 \\
\end{tabular} & 2.158 & \begin{tabular}{|l|l|}
8 & 10.9 \\
\end{tabular} & \begin{tabular}{l|l}
5 & 1.378 \\
\end{tabular} & 4925733.5 & 171.00 & 0.22 \\
\hline SCBL & 0.37 & & $\begin{array}{lll}0.42 & 0.4\end{array}$ & $\begin{array}{l}710.8 \\
\end{array}$ & & 0.14 & 23.52 & 2.1 & 3.41 & 4125.42 & 33.71 & 82.44 & 36.89 & $\begin{array}{ll}9 & 6 . \\
\end{array}$ & 92.653 & \begin{tabular}{|l|l|}
3 & 12.42 \\
\end{tabular} & 1.918 & \begin{tabular}{l|l}
8 & 14.3 \\
\end{tabular} & \begin{tabular}{l|l}
4 & 0.007
\end{tabular} & 3555531.25 & 263.25 & \begin{tabular}{|l|l|}
5 & 0.30 \\
\end{tabular} \\
\hline Himalayan & 0.23 & & \begin{tabular}{l|l}
0.26 & 0.7 \\
\end{tabular} & 56.99 & & 1.56 & 47.12 & 4.5 & 2.21 & 1864.29 & 28.05 & 44.58 & 20.83 & 2. & \begin{tabular}{|l|l|}
6 & 1.693 \\
\end{tabular} & \begin{tabular}{|l|l|}
3.99 \\
\end{tabular} & 1.870 & $\begin{array}{ll}0 & 10.8 \\
\end{array}$ & 62.998 & 3843968.68 & 219.02 & 20.19 \\
\hline Everest & 0.30 & & \begin{tabular}{l|l|l}
0.33 & 0.7 \\
\end{tabular} & \begin{tabular}{l|l}
5 & 14.1 \\
\end{tabular} & & 0.51 & 10.43 & 4.7 & \begin{tabular}{|l|}
5.7 \\
\end{tabular} & 2344.34 & 17.51 & 92.97 & 16.41 & & .92 .008 & \begin{tabular}{l|l|}
8 & 8.75 \\
\end{tabular} & 2.143 & \begin{tabular}{l|l}
3 & 10.8 \\
\end{tabular} & 90.455 & 2982825 & 316.74 & 4. 0.25 \\
\hline
\end{tabular}


IJAHP Article: Mu, Saaty/A Style Guide for Paper Proposals To Be Submitted to the International Symposium of the Analytic Hierarchy Process 2014, Washington D.C., U.S.A.

\subsection{Performance Evaluation of Banks by AHP}

Table 2: Pairwise Comparison Matrix with respect to Goal

\begin{tabular}{|l|l|l|l|l|l|}
\hline & Liquidity & Efficiency & Profitability & CAR & $\begin{array}{l}\text { Asset } \\
\text { Quality }\end{array}$ \\
\hline Liquidity & 1.0 & 2.5 & 1.7 & 2.1 & 1.3 \\
\hline Efficiency & 0.4 & 1.0 & 0.9 & 0.6 & 1.3 \\
\hline Profitability & 0.6 & 1.1 & 1.0 & 0.7 & 0.5 \\
\hline CAR & 0.5 & 1.7 & 1.5 & 1.0 & 1.5 \\
\hline $\begin{array}{l}\text { Asset } \\
\text { Quality }\end{array}$ & 0.8 & 0.8 & 1.0 & 0.6 & 1.0 \\
\hline
\end{tabular}

The overall inconsistency was 0.04 which is $<0.1$

Based on Pair wise Comparison of the Financial Criteria's and Sub Criteria It was seen that Liquidity in Banks ( $\mathrm{W}=0.311)$ Capital Adequacy $(\mathrm{W}=0.216)$ Asset Quality $(\mathrm{W}=0.185)$ Efficiency $(\mathrm{W}=0.149)$ and Profitability $(\mathrm{W}=0.139) . \quad \mathrm{L} 3=$ Total Credit/Total Deposit ratio has a Global weight of 0.95. Further the Data Grid function in Expert Choice software was used to assess the relative importance of the financial parameters based on the maximum and minimum value of the financial data. The sensitivity analysis showed that the relative ranking of two public sector banks Rastriya Banijya Bank could be improved if Capital Adequacy factor is improved.

Figure 2: Normalized Ranking of Commercial Banks

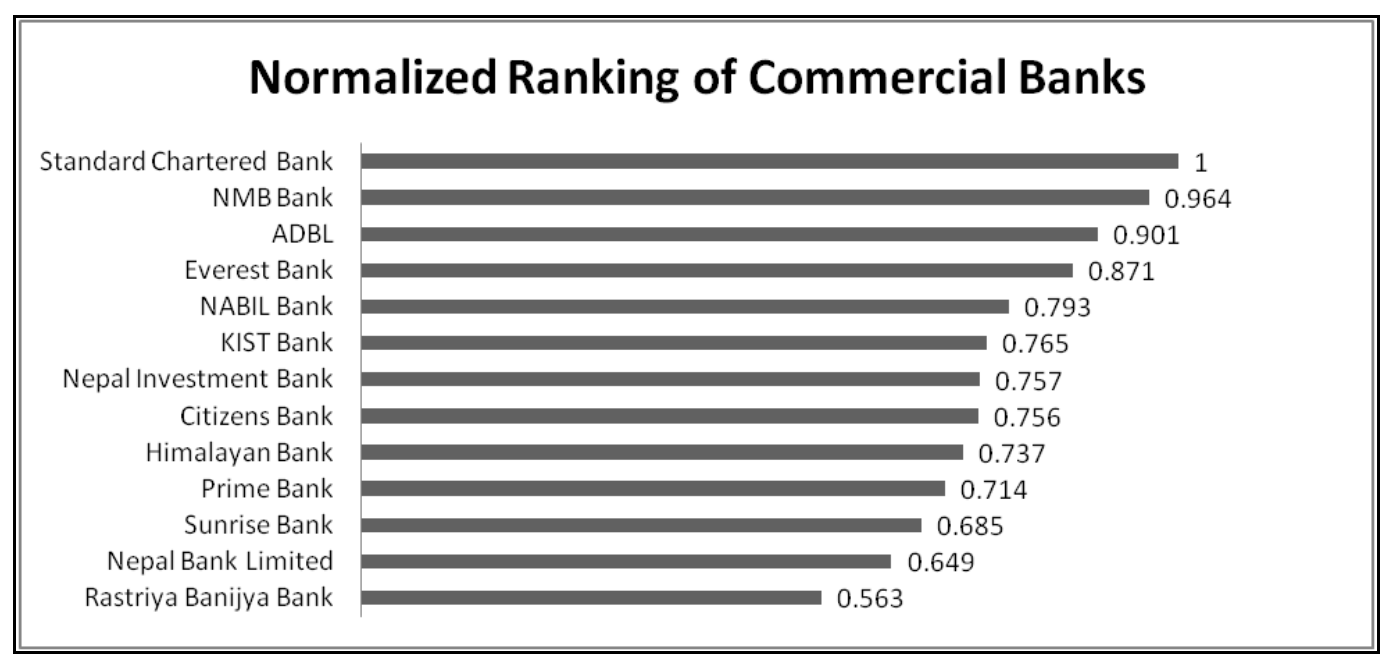

\section{Limitations}

1) This study is limited to only a period of 4 years trend and of 13 commercial banks of the concerned banks and hence the conclusion drawn confines only to the above period and banks.

2) This study is particularly based on the data as derived from the published annual report of thirteen banks along with NRB directives and does not consider 
IJAHP Article: Mu, Saaty/A Style Guide for Paper Proposals To Be Submitted to the International Symposium of the Analytic Hierarchy Process 2014, Washington D.C., U.S.A.

Management Efficiency, Market Risks and Customer Satisfaction to evaluate bank performance.

\section{Conclusions}

The ranking of commercial banks was done after prioritization of the financial criteria's. Two Public sector banks Nepal Bank Limited and Rastriya Banijya Bank were ranked in the bottom two in the ranking list. Further a Sensitivity analysis shows an apparent Capital Adequacy risk for Nepal Bank Limited and Rastriya Banijya Bank which has to be improved significantly. This study has added one more literature to demonstrate the utility of AHP based bank evaluation to Nepalese banking community in particular, which not only evaluates the performance of banks but also gives insights to focus in the area of improvement to a particular bank in comparison to others. The ability of dynamic sensitivity analysis feature available with the AHP processing software further helps to overcome the accuracy of data presented by the individual banks, which could be the added value to Bank regulators.

\section{REFERENCES}

Abalameli, Farkhonde and Rasolinezhad, Ehsan. (2011).The Ranking of Chosen Branches of Saderat Bank in Tehran City Through the AHP and the DEA/AHP Model. Proceedings of the International Symposium on the Analytic Hierarchy Process.

Babić, Z, Belak, V and Tomić-Plazibat, N. (1999) Ranking of Croatian banks according to business efficiency.. Preddvor,Slovenia. Proceedings of the 5th International Symposium on Operational Research.

Bhattarai, Shashi and Shivjee, Yadav Roy (2009). AHP Application in Banking: Unfolding Utility in a Situation of Financial Crisis., Proceedings of International Symposium on Analytic Hierarchy Process (ISAHP 2009).

Čehulić, Dejan, Hunjak, Tihomir and Begičević, Nina. Croatia (2011). Comparison of a Bank's Financial Ratios Using the Analytic Hierarchy Process.. Proceedings of the 22nd Central European Conference on Information and Intelligent Systems. pp. 187-193.

Hanley, C. A., \& Suter, M. P. (1997). Banking's top performance. ABA Banking Journal 89 (7), 36-40.

Dang, Uyen (2011). The CAMEL Rating System in Banking Supervision A Case Study. s.l. : Arcada University of Applied Sciences, International Business, 2011.

Nepal Rastra Bank. (2012). Bank Supervision Report. s.l.: Bank Supervision Department, Nepal Rastra Bank.

Saaty, T.L. (1980). The Analytic Hierarchy Process: Planning, Priority Setting, Resource Allocation, McGraw-Hill, Inc. 